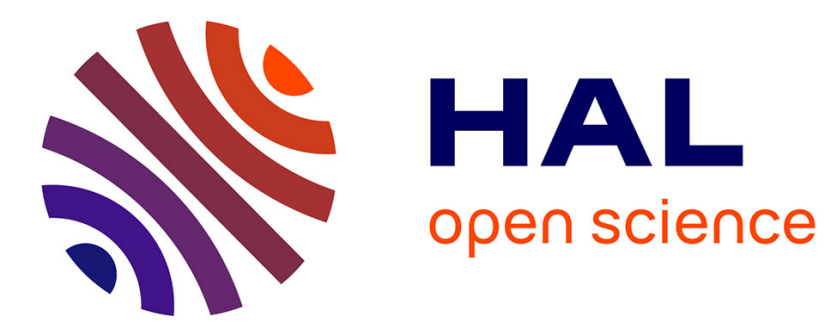

\title{
Age and egg-sac loss determine maternal behaviour and locomotor activity of wolf spiders (Araneae, Lycosidae)
}

Fanny Ruhland, Violette Chiara, Marie Trabalon

\section{To cite this version:}

Fanny Ruhland, Violette Chiara, Marie Trabalon. Age and egg-sac loss determine maternal behaviour and locomotor activity of wolf spiders (Araneae, Lycosidae). Behavioural Processes, 2016, 132, pp.5765. 10.1016/j.beproc.2016.09.011 . hal-01375498

\section{HAL Id: hal-01375498 \\ https://hal-univ-rennes1.archives-ouvertes.fr/hal-01375498}

Submitted on 5 Jan 2017

HAL is a multi-disciplinary open access archive for the deposit and dissemination of scientific research documents, whether they are published or not. The documents may come from teaching and research institutions in France or abroad, or from public or private research centers.
L'archive ouverte pluridisciplinaire HAL, est destinée au dépôt et à la diffusion de documents scientifiques de niveau recherche, publiés ou non, émanant des établissements d'enseignement et de recherche français ou étrangers, des laboratoires publics ou privés. 


\section{Age and egg-sac loss determine maternal behaviour and locomotor activity of wolf spiders (Araneae, Lycosidae)}

Fanny Ruhland, Violette Chiara, Marie Trabalon’

University of Rennes 1, UMR 6552 CNRS EthoS, Rennes, France

Highlights

- Age of egg-sac affects the behaviour of mother.

- Locomotor activity of mother is not modified with egg-sac age.

- Mothers show a searching behaviour and higher activity after losing their egg-sacs.

- Mothers with older cocoons are most active in searching their cocoon.

- All mothers found their lost cocoon and showed maternal behaviour towards it.

\section{Abstract}

Wolf spiders' (Lycosidae) maternal behaviour includes a specific phase called "egg brooding” which consists of guarding and carrying an egg-sac throughout the incubation period. The transport of an egg-sac can restrict mothers' exploratory and locomotor activity, in particular when foraging. The present study details the ontogeny of maternal behaviour and assesses the influence of age of egg-sac (or embryos' developmental stage) on vagrant wolf spider Pardosa saltans females' exploration and locomotion. We observed these spiders' maternal behaviour in the laboratory and evaluated their locomotor activity using a digital activity recording device. Our subjects were virgin females (without egg-sac) and first time mothers (with her egg-sac) who were divided into three groups. The first group of mothers were tested on the day the egg-sac was built (day 0), and the females of the other two groups were tested 10 or 15 days after they had built their egg-sac. We evaluated the effects of the presence and the loss of egg-sac on mothers' activity. Pardosa saltans females' behaviour depended on mothers' physiological state and/or age of egg-sac (developmental stage of embryos). Virgin females' behaviour was not modified by the presence of an egg-sac in their environment. Mothers' reactions to the presence, the loss and the recovery of their egg-sac varied during the maternal cycle. Maternal behaviour changed with age of egg-sac, but the levels of locomotor activity of mothers with egg-sacs was similar to those of virgin females. Loss of egg-sac modified the maternal behaviour and locomotor activity of all mothers; these modifications were greater on "day 15" when embryos had emerged from eggs. All mothers were able to retrieve their egg-sacs and to re-attach them to their spinnerets.

\section{Introduction}


Either one or both parents in many different groups of animals take care of their fertilized eggs (see Clutton-Brock 1991; Royle et al., 2013). This is a necessity for most oviparous endotherms as well as some ectotherms as it helps control offspring's abiotic and biotic environmental factors (water balance, thermoregulation, and to protect them from predators and parasites) (Hieber 1992; Humphrey 1974; Norgaard 1951). Egg care is uncommon among terrestrial arthropods, perhaps because parents are seldom able to protect their young effectively, and selection favours the production of a large number of eggs (Lardies et al., 2004; Tallamy \& Wood 1986; Tammaru et al., 2002). Arthropods' egg care can be divided into two types: egg attendance and egg brooding (Smiseth et al., 2012). Egg attendance occurs when parents remain with their eggs at a fixed location, usually the oviposition site, after eggs have been laid. Egg brooding is a form of parental care when parents carry their eggs after laying. Egg brooding could offer more advantages than egg attendance when parents breed in unpredictable environments because brooding would then allow parents to move about more freely while still caring for their eggs (Smiseth et al., 2012).

Some members of the Thomisidae, Pisauridae, Salticidae, and Lycosidae spider families (Bristowe 1958; Eason 1964, 1969; Peck \& Whitcomb 1970; Rovner et al., 1973; Whitcomb \& Eason 1964) brood eggs and thus increase offspring fitness by providing protection against egg predators (Nørgaard 1956; Kaston 1965; Shear 1970; Kullmann 1972; Eberhard 1974; Brach 1976; Gertsch 1979; Buskirk 1981), parasitism (Lubin 1974), and optimal thermoregulation conditions for their development (Bradoo 1973; Humphreys 1974; Nørgaard 1951, 1956; Vlijm et al., 1963). Furthermore, parents' costs may be lower for brooding than for attending because brooding parents can forage more easily while still caring for their eggs. However, the additional mass of eggs usually restricts locomotion and, consequently decreases foraging efficiency and increases predation risk (Kight \& Ozga 2002). Thus, maternal investment of egg-carrying species such as wolf spiders increases with time, incurring metabolic and ecological costs. Reports on the conditions of onset, maintenance and extinction of maternal care of egg-sacs suggest complex interactions between internal factors (mothers' physiological state) and external factors (i.e. stimulations from the embryos) (Bonnet 1946; Norgaard 1956; Krafft and Horel 1980; Vannini et al., 1986; Horel and Gundermann 1992; Roland et al., 1996). The commonly held view is that arthropods' maternal behaviour is the stereotyped expression of a genetic programme. While some lycosid females refuse an egg-sac when they have not yet oviposited (Palmgern 1944), virgin Schizocosa ocreata females adopted an egg-sac offered and reared the spiderlings that emerged from it as if they were their own (Wagner 1995). This indicates that induction of maternal care is possible in spider as in vertebrates.

Females wolf spiders' (Lycosidae) egg brooding can be divided into the following stages: construction of sac (or cocoon), care of egg-sac, perforation of egg-sac, and transport of spiderlings after their emergence from the cocoon (Vlijm et al., 1963; Eason 1964; Whitcom \& Eason 1967; Randall 1977; Gertsch 1979; Wise 1993; Dolejš et al., 2010; Foelix 2011). While egg-sacs are being carried embryos develop into eggs, and then they hatch from the egg as partly developed pre-larvae (Vachon 1957). They moult at least once (larva or juvenile stage) before leaving the egg-sac (Canard, 1987). No reports describe the ontogeny of maternal behaviour after egg-sac building and none have studied the effects of the developmental stage of eggs on vagrant mothers' exploratory and locomotor activities. Moreover, the locomotor activity of free-moving members of the genus Pardosa (Lycosidae) is important (Fujii 1977; Gertsch 1979), they forage on the ground and in the leaf litter of a wide variety of terrestrial habitats (Nyffeler et al., 1994; Wise 1993). Mothers trail their eggsacs behind them attached to their opisthosoma (or abdomen) or their spinnerets for several weeks. In their natural environment, an egg-sac can become detached when a female forages and moves about actively. A female can search for her egg-sac after losing it (Colancecco et 
al., 2007; Culley et al., 2010; Fujii 1980; Wagner 1995) and can reattach it after she has found it (Colancecco et al., 2007; Culley et al., 2010; Eason 1964; Foelix 2011). However, mothers' exploratory behaviour and locomotor activity after losing and reattaching her egg-sac are undocumented.

We questioned whether egg-sac brooding is strictly programmed (through autonomous maturational processes) with oviposition, or is influenced by external factors (as stimuli from offspring). We hypothesized 1) that maternal behaviour cannot be accounted for by spontaneous endogenous changes (oviposition), but that it is induced and maintained by stimulations from the egg-sac that would depend on its age (embryos' developmental stage); 2) that mothers' exploratory and locomotor activities when searching for a lost egg-sac would vary during the maternal care period. We compared the behavioural sequences, exploratory and locomotor activities, under laboratory conditions, of vagrant wolf spiders, Pardosa saltans mothers (Töpfer-Hofmann 2000) between unloaded spiders (virgins) and spiders with egg-sacs (mothers). We expected 1) that behavioural patterns would change after oviposition and construction of egg-sac, and that maternal care and locomotor activity would change in relation to age of egg-sac; 2) that after loss of egg-sac, mothers' exploratory and locomotor activities, recovery and rehanging of egg-sac would differ in relation to the time they had already invested in maternal care (mothers with older egg-sacs would search longer for it).

\section{2- Methods}

The spiders of the genus Pardosa account for the largest number of lycosid species in Europe and are the most abundant and common genus. Pardosa saltans was described in 2000, but its biology and behaviour have not been studied and its maternal behaviour has never been described. No observations of females' locomotor activity have been made during the maternal period. Females become very conspicuous from May or June onwards, when they begin carrying around their egg-sacs. Females can reproduce twice, but invest most during the first cycle, in summer, whereas in autumn egg-sacs, if any, are lighter (although with larger eggs) (personal observations, unpublished data). Our observations, restricted to the laboratory, show that egg-sacs remain attached to the maternal spinnerets by silk threads for about 25 days. The fact that, while carrying egg-sacs, females continue to be mobile while feeding (unpublished data) makes them ideal models to study trade-off between maternal behaviour and locomotor/foraging activity.

Our Pardosa saltans female subjects were virgin adults collected during the copulation period and captured in a forest near the biological station of Paimpont (University of Rennes 1 propriety; France; 4800’05.67" North, 2¹3’46.65" West) during April-May 2015. Females were kept individually in circular terrariums $(10 \mathrm{~cm}$ diameter $\mathrm{x} 5 \mathrm{~cm}$ high) with water and without soil, and were bred at $20 \pm 1{ }^{\circ} \mathrm{C}, 56 \pm 1 \%$ relative humidity under a L:D, 8:20 h photoperiodic cycle. Spiders were fed every three days ad libitum with juvenile crickets (Acheta domestica) alternating with adult flies (Delia radicum). All mated females were checked at least twice a day (morning and evening) to record oviposition.

$<\mathrm{H} 2>2$.1. Embryos' developmental stage in relation to age of egg-sac

In order to see if characteristics of the egg-sac are modified during the ontogeny different measurements were done. To measure egg-sacs, they were removed rapidly with a brush from mothers with a "Day 0" $(n=10)$, "Day 10" $(n=10)$, or "Day 15" $(n=10)$ cocoon. Cocoons were weighed (Sartorius electronic balance, $\pm 0.01 \mathrm{~g}$; Palaiseau, France), measured on micrographs and then the egg-sacs were opened. Eggs were counted in the cocoon on "day 0 ", embryos' developmental stage was assessed in the cocoon on "day 10" and on "day 15". The equation for a probate spheroid, $\mathrm{V}=4 / 3 \pi\left(a b^{2}\right)$, where $\mathrm{a}=$ length and $\mathrm{b}=$ width of the egg-sac (in $\mathrm{mm}$ ), was applied to determine the volume of egg-sacs. 


\section{$<\mathrm{H} 2>2.2$. Maternal behaviour sequences during egg brooding in terrarium}

The behaviour of 20 mothers in their terrarium was recorded: just after oviposition, construction and attachment of the egg sac ("Day 0"), after 10 days ("Day 10"), after 15 days of egg-sac care ("Day 15"), and when young emerged from their egg-sac. All behaviours displayed by the mothers in their brooding terrarium were recorded: auto-centred behaviours and those involving their egg-sac. All observations were made ten minutes per hour per state during daytime (between 8.00 and 19.00 hours) in natural light and were recorded using a Canon HD (HG20) camera.

$<\mathrm{H} 2>2.3$. Exploratory behaviour and locomotor activity of females in a novel environment

Two experimental groups were observed in a glass arena $(10 \mathrm{~cm}$ diameter and $5 \mathrm{~cm} \mathrm{high):} 14$ "virgin" young females (not mated) were controls and 57 "mothers with an egg-sac" during the first maternal care cycle on "Day 0" $(\mathrm{n}=19)$, on "Day 10" $(\mathrm{n}=19)$, and then on "Day $15 "(\mathrm{n}=19)$. All subjects were observed during the same period of day (between 8.00 and 12.00 hours) under natural light. All females were given one fly the day before the experiment and tested the following day only if the prey had been consumed (so that the activity observed was exploration of the novel environment and not foraging). Two of arenas were used simultaneously so we could pair subjects with different physiological states, combining all possibilities (virgin/mother, "day 0"/“'day 10", "day 0"/“'day 15", " day 10"/“day 15", etc). This methodological precaution aimed to counteract effects of changes in temperature and humidity on the spiders' behaviour. To eliminate bias due to the positions of the arenas, we alternated the physiological groups between sides between trials. The arenas were washed with water then ethanol $(70 \%)$ between trials to eliminate any possible intraspecific cues that could influence activity. All the behaviours observed in the terrariums (self-centred and involving egg-sac) were recorded in this novel environment. We monitored spiders' exploratory and locomotor activities during each trial. The coordinates of females were recorded every 12 frames / second using a Canon HD (HG20) camera and an automated video-based, digital-data collection system (Swiss-Track software 4.0.0 with the nearest neighbour tracking method). We measured surface explored (percentage) and distance covered ( $\mathrm{cm} / \mathrm{min}$ ) with the $\mathrm{R}$ software (R 3.0.2). Distance covered was calculated every 4 frames per second. When distances covered were less than $3.33 \mathrm{~mm} / \mathrm{sec}$ they were not taken into account.

Three tests assessed females' activities:

\section{Test 1: during egg-sac carrying}

A subject, either a virgin or a mother with her egg-sac was placed in the centre of the arena under a vial (1.5 cm diameters) $1 \mathrm{~min}$ before the test started. The vial was removed and the subject was allowed $5 \mathrm{~min}$ to habituate to the arena prior to data collection. After this period, the spider's activity was monitored for $10 \mathrm{~min}$.

At the end of a test, all spiders (virgins and mothers with egg-sac) were anesthetized in the arena by chilling at $5^{\circ} \mathrm{C}$ for $5 \mathrm{~min}$. Egg-sacs were removed from their mothers rapidly with a brush. Egg-sacs were transferred individually into a vial and stored at room temperature. Virgins and mothers woke up after $1 \mathrm{~min}$ at room temperature and were placed under a vial in the centre of the arena just before test 2 .

- Test 2: after the loss of egg-sac

Mothers without their egg-sac and virgin spiders (to assess the effects of anaesthesia and manipulation) were tested following the same procedure as for test 1 . The spider's activity 
was monitored for $10 \mathrm{~min}$. Then, at the end of test 2 , the egg-sac was placed in the arena opposite the female, $3 \mathrm{~cm}$ away. Virgin females were tested with a 15-day old "unknown egg-sac" (to assess the influence of females' physiological state on egg-sac acceptation) and mothers were tested with their own egg-sac. To evaluate the efficiency of egg-sac search and the rapidity to return to the normal situation (egg-sac attached to the spinnerets) we recorded: time taken by females to find their egg-sac, durations of egg-sac manipulation (time between first contact and manipulation of cocoon with a leg or a pedipalp, and first contact with abdomen) and egg-sac hanging (time between contact of egg sac with abdomen and attachment to spinnerets). When a female had not contacted or attached her egg-sac after 30 min, the egg-sac was considered "not retrieved".

- Test 3: after hanging of egg-sac

Females' exploratory and locomotor activities were recorded for $10 \mathrm{~min}$ after they had retrieved their egg-sac.

At the end of test 3, all mothers with their egg-sac were replaced in their terrarium until emergence of spiderlings.

\section{$<\mathrm{H} 2>2.4$. Statistical Analysis}

Data are expressed as means \pm SE. Statistical analyses were performed using $\mathrm{R}$ software (3.0.2) (R Core Team, 2013). Differences were estimated using analyses of variance (one-way ANOVA with repeated variable). Surface area explored were divided by 100 and then converted to $\sqrt{ }$ arcsine proportions to normalize data before an ANOVA was computed. When differences between means were significant at the $p<0.05$, and a posteriori Tukey's (HSD) tests established the inter-group comparison. Frequencies of behaviours were analysed using $\chi^{2}$ tests and a Bonferroni's correction was applied. In all cases, the differences were considered significant at $\mathrm{p}<0.05$.

\section{$<$ H1 $>3$ - Results}

$<\mathrm{H} 2>3.1$. Embryos' developmental stage in relation to age of egg-sac

Soon after copulation (14 \pm 1 days) and immediately after oviposition (44-23 eggs; $35 \pm 10$ eggs), the females started to construct then attach their egg-sac to their spinnerets (Fig. 1). Under our laboratories conditions, after 10 days incubation, embryos, at the first pre-larva stage (with incomplete extremities and yolk reserves) were visible in eggs. After 15 days, a white seam appeared all round the grey-bluish egg-sac and $2^{\text {nd }}$ stage pre-larvae (segmented legs and poor mobility) started to hatch from the egg. Weights $(15.29 \pm 0.77 \mathrm{mg})$ and volumes $\left(13.97 \pm 0.37 \mathrm{~mm}^{3}\right)$ of cocoons on days 0,10 and 15 were similar $\left(F_{2,43}=2.26 \mathrm{p}=0.07\right.$ and $\left.\mathrm{F}_{2,43}=1.84, \mathrm{p}=0.18\right)$.

$<\mathrm{H} 2>3.2$. Maternal behaviour during egg-sac care in terrarium

After oviposition and while carrying their egg-sac, females' behaviours included raising and lowering one of their first pair of legs (= "waving"), passing a leg or a pedipalp between their chelicera (= "grooming"), hitting the ground with their first pair of legs (= "hitting"), putting their egg-sac under their cephalothorax attached to an abdominal fold so that their pedipalps and first and third pairs of legs could be in contact with the egg-sac (= "egg sac under cephalothorax"), detaching their egg-sac from their spinnerets and turning it with their 
pedipalps and first and third pairs of legs (= "egg-sac manipulation") (cf. movie files, supplementary data). When spiderlings started to hatch their mothers assisted their emergence: females then rotated their egg-sac with their legs and palps and cut the seam of the egg-sac with their chelicerae. As the egg-sac was torn apart, the young started coming out and climbing onto their mother's back.

$<\mathrm{H} 2>3$.3. Test 1: Influence of egg-sac age on females' exploratory behaviour and locomotor

\section{activity in a novel environment}

The exploration of a novel environment by mothers "with an egg-sac" varied significantly with the age of their cocoon $\left(\chi^{2}=108.8, \mathrm{df}=8, \mathrm{p}<0.0001\right)$. On "Day 0" mothers only "waved" and "groomed" their legs and pedipalps (Fig. 2A). These females' behaviour did not differ from that of "virgins". Mothers on "Day 10" expressed significantly more "waving" and manifested "hitting" activity. Only mothers on "Day 15" expressed two behaviours involving their egg-sac: placing "egg-sac under cephalothorax" and "egg-sac manipulation". Both virgins and mothers walked preferentially close to the periphery of the arena (Fig. 3C). Mothers carrying an egg-sac raised their opisthosoma during exploration, gathering their legs more closely under themselves. Mothers' locomotor activity did not vary significantly during the egg-sac care period and was similar to that of virgin females (distance covered: $F_{3,67}=$ $0.68, p=0.51$; surface explored: $F_{3,67}=0.85, p=0.47$ ) (Fig. $3 \mathrm{~A}$ and $3 B$ ). Distances covered by mothers with an egg-sac ranged from 16.5 to $19.2 \mathrm{~cm} / \mathrm{min}$, and mothers explored approximately $40-50 \%$ of the arena surface.

$<\mathrm{H} 2>3$.4. Test 2: Females' activity after loss of egg-sac in relation to age of egg-sac

Mothers modified their behaviour significantly after losing their egg-sac ( 'Day 0 ": $\chi^{2}=97.12$, $\mathrm{df}=5, \mathrm{p}<0.0001$; “Day 10": $\chi^{2}=99,55, \mathrm{df}=5, \mathrm{p}<0.0001$; "Day 15": $\chi^{2}=143,06, \mathrm{df}=5, \mathrm{p}$ $<0.0001)$; the females' reactions to this loss varied with age of egg-sac $\left(\chi^{2}=3813, \mathrm{df}=6, \mathrm{p}<\right.$ 0.0001) (Fig. 2B). Mothers on "Day 0" and on "Day 10" expressed "hitting" and two new activities: females hunched their legs and palps under themselves staying in maximum contact with the ground (="'hunch") and made lateral movements of their abdomen (="abdominal movement"). Mothers on "Day 15" also expressed "hunch" and "abdominal movement" but not "hitting". "Hunch" was the motor act expressed the most frequently (50-71\%) by the mothers after egg-sac loss. Mothers on "Day 0" made significantly fewer "abdominal movements" and "waved" more than on "Day 10" and "Day 15" $(\mathrm{p}<0.0001)$. Mothers "waved" $(p=0.043)$ and "hit" significantly more frequently on "Day 10" than on "Day 15" $(\mathrm{p}<0.0001)$.

While exploring, mothers without an egg-sac maintained their opisthosoma in a straight line in relation to their prosoma and parallel to the substratum, as did virgins. All mothers moved significantly more than did virgin females (distance covered: $F_{(3,67)}=27.29, p<0.0001$; surface explored: $\mathrm{F}_{(3,67)}=22.65, \mathrm{p}<0.0001$ ) (Figure $3 \mathrm{~A}$ and $3 \mathrm{~B}$ ). Mothers covered similar distances on "Day 0" and on "Day 10", but on "Day 10" mothers explored significantly larger surfaces than on "Day 0 " $(\mathrm{p}=0.005)$. Mothers moved and explored significantly more on "Day 15" than on "Day 0" ( $\mathrm{p}=0.04)$ and "Day 10" $(\mathrm{p}<0.001)$. Furthermore, the mothers' locomotor patterns were modified during this test: from straight displacements when they had an egg-sac attached to their spinnerets (test 1), their trajectories winding more after losing their egg-sac Fig. 3C).

$<\mathrm{H} 2>3.5$. Test 3: Females' activity before and after hanging egg-sac in relation to age of egg- 
After introduction of their egg-sac in the arena, mothers did not go directly to their egg-sac but followed winding trajectories until either their palps or one of their first three pairs of legs randomly contacted it. Delays to contact egg-sac and manipulate it did not differ significantly between mothers on "Day 0", "Day 10" and "Day 15": mothers recovered and contacted the egg-sac after $197 \pm 46 \mathrm{sec}\left(\mathrm{F}_{2,54}=0.004, \mathrm{p}=0.95\right)$ and manipulated the egg-sac for $30 \pm 4 \mathrm{sec}$ $\left(\mathrm{F}_{2,54}=0.46, \mathrm{p}=0.64\right)$ (Fig. 4). Mothers hung their egg-sacs significantly more rapidly on "Day 0" than on the other days ("Day 0": $65 \mathrm{sec}$; "Day 10" and "Day 15": 108-125 sec; $F_{2,54}$ $=3.12, \mathrm{p}=0.05)$.

Females' recovery reactions did not vary with age of egg-sac $\left(\chi^{2}=9.71, \mathrm{df}=5, \mathrm{p}=0.084\right)$ (Fig. 2C). However, experiencing loss modified significantly mothers' behaviour after cocoon hanging $\left(\chi^{2}=18.89, \mathrm{df}=8, \mathrm{p}=0.01\right)$. "Day 0 " mothers expressed the same behaviours after hanging as in test 1 . "Day 10" mothers behaviours were similar to those during test 1 but their frequencies differed significantly $\left(\chi^{2}=26.85, \mathrm{df}=4, \mathrm{p}=0.001\right)$. " Day 15" mothers "groomed" more than during test $2\left(\chi^{2}=137.37, \mathrm{df}=5, \mathrm{p}=0.0001\right)$. "Day 15" mothers did not manipulate their egg-sac during test 3 like they did in test 1.

Mothers' locomotor activity following egg-sac hanging did not vary with age of egg-sac (distance covered: $F_{(3,67)}=1.47, p<0.23$; surface explored: $F_{(3,67)}=0.67, p<0.57$ ) (Fig. $3 \mathrm{~A}$ and $3 \mathrm{~B}$ ). Their locomotor activity was then similar to that observed before loss of egg-sac during test $1\left(\mathrm{~F}_{3,67}=1.47, \mathrm{p}=0.23\right)$ and was significantly lower than during test $2\left(\mathrm{~F}_{3,67}=\right.$ $37.40, \mathrm{p}<0.0001)$. Mothers carrying an egg-sac raised their opisthosoma during exploration, gathered their legs more closely under them, and their displacements were straight similar to those observed during test 1 (Fig. 3C).

The fact that virgin females' behaviour $\left(\chi^{2}=0.43, \mathrm{df}=3, \mathrm{p}=0.93\right)$ and locomotor activity did not vary significantly between tests (distance covered: $\mathrm{F}_{(3,39)}=0.85, \mathrm{p}<0.47$; surface explored: $\left.\mathrm{F}_{(3,39)}=1.03, \mathrm{p}<0.59\right)$, showed that anaesthesia and/or manipulations related to the experiment did not influence spiders' behaviour or locomotor activity. Moreover, none of the virgin females manipulated or hung "a live unknown" egg-sac.

$<$ H2 $>$ 3.6. Maternal care until emergence of young

Mothers in their terrarium carried their egg-sac attached to their spinnerets until spiderlings hatched and egg-sac guarding lasted $25 \pm 2$ days. When spiderlings were ready to hatch the female spiders opened their egg-sac to let the spiderlings emerge. Young emerged from all test egg-sacs $(\mathrm{n}=57)$.

\section{$<$ H1 $>4$ - Discussion}

\section{$<\mathrm{H} 2>4$.1. Behaviour and locomotion during cocoon care}

Our observations show that two behavioural acts are common to virgin and mother $P$. saltans: "waving" and "grooming". These behaviours are probably not related to cocooning, but to exploration of the environment (Eason 1969; Escalante et al., 2015; Hebets et al., 1996; Miller \& Miller 1987; Papke et al., 2001; Roberts \& Uetz 2004; Rundus et al., 2015). Only mothers with "day 10" and "day 15" egg-sacs hit the ground with their first pair of legs. This "hitting" behaviour is an exploration act developed by mothers and could be a vibratory stimulus for embryos. The cocoon is never in contact with the ground during mothers' locomotor activity. Thus embryos might not perceive vibrations transmitted by the ground. However, we suppose that "hitting" enables vibrations due to the percussion of legs to be transmitted to the egg-sac through the opisthosoma. These vibrations could enhance the development of embryos' sensory organs (Barth 2015; Foelix 2011). Mothers with "day 15" cocoons manifested previously unobserved behaviours oriented towards their egg-sac: they placed their egg-sac under their cephalothorax, detached it from their spinnerets and 
manipulated it with their third pair of legs. Egg-sac manipulations appeared on "day 15", when mobile embryos ( $2^{\text {nd }}$ stage pre-larvae) produced vibrations which could stimulate cocoon manipulations as reported for other spiders (Krafft 1981; Lubin 1974; Viera et al., 2007). These egg-sac manipulations are considered maternal care, and appear progressively with age of cocoon and more precisely after hatching of the embryo in the egg-sac. We suppose that stimuli emitted by mobile embryos (cf. movie files, supplementary data) in the egg-sac, together with mothers' physiological changes, are necessary to maintain and develop maternal care as for other species (Palmgern 1944; Horel \& Gundermann 1992; Krafft \& Horel 1980; Culley et al., 2010).

Our results show that females' horizontal locomotor activity was not modified by the presence of an egg-sac and that the age of a cocoon did not influence locomotion. Pardosa saltans mothers' and virgin females' locomotor activities were similar, only moving round the periphery of the arena and their locomotion was straight. This locomotion is possible for mothers carrying an egg-sac due to a modification of the position of their legs and of the protraction / retraction ratios, as for P. tristis (Moffett \& Doell 1980). Nevertheless, females carrying an egg-sac adopted a more elevated stance than did virgin spiders like $P$. tristis (Moffett \& Doell 1980). Raising their opisthosoma when an egg-sac is attached may protect the egg-sac from injury in rough terrains where these spiders live, and it may keep their eggsac out of the way of their back legs.

$<\mathrm{H} 2>4$.2. Behaviour and locomotion after cocoon loss

Cocoon loss affected the behaviour and the locomotion pattern of all mothers. Their locomotor activity increased, covering about 40 to $50 \mathrm{~cm} / \mathrm{min}$ and they explored the arena completely following winding trajectories. The fact that virgins' behaviour and locomotor activity were not modified after anaesthesia and/or manipulations related to the tests shows that modifications of mothers' behaviour and locomotion were related to egg-sac loss. After egg-sac loss, mothers developed two new behaviours: "hunching" and "abdominal movements". The spiders are known to use multimodal cues, such as vibratory and chemical signals, to orientate in their environment. For example, they broadcast vibratory signals with specific movements hitting the ground with their first pair of legs, palps or opisthosoma (Bonnet 1946; Seyfart \& Barth 1972). Furthermore, mothers' "abdominal movements" recall spiders' chemical marking during sexual or foraging exploration (Tietjen 1977). We suggest that mothers who had lost their egg-sac expressed these two behaviours to detect the lost eggsac, and/or to explore a larger surface.

As these modifications increase the efficiency of mothers' exploration, they could be associated with searching. This "searching" behaviour was observed from the first day of cocooning and its frequencies increased with age of cocoon. Embryos' normal development and emergence must be facilitated by their mother, so loss of egg-sac means death of offspring. All spider species can produce additional egg sacs if their previous egg-sac is removed (Fink 1987; Marques et al., 1998; Stefani et al., 2011; Toyama 2003). Females have the physiological ability to produce additional eggs, but may be limited in the number of offspring they can care for without negatively impacting their residual fitness. A mother who has just produced a cocoon has spent a great deal of energy and she cannot produce another one rapidly. So it is advantageous for her to find her egg-sac. Females' metabolic and ecological costs for egg-sac carrying are high (Eason 1964; Fujii 1977; Gertsch 1979; Li \& Jackson 2003). Mothers' maternal effort increases with age of egg-sac due to their previous overall investment in maternal care and egg-sac carrying. That is why searching varied with egg-sac age, increasing with time spent with an egg-sac.

$<\mathrm{H} 2>4.3$. Behaviour and locomotion after discovery of the cocoon 
When the egg-sac had been found, all the mothers attached their egg-sac after touching it. None of the virgin females attached an egg-sac. This confirms that maternal behaviour is linked to the act of oviposition (Opell 2001; Horel and Gundermann, 1992; Wagner 1995). Ortega-Escobar (2011) observed that Lycosa tarantula can see fixed contrast differences. If $P$. saltans ' vision is similar to that of $L$. tarantula, females should be able to locate the greybluish egg-sac on a white surface even if is immobile. However, P. saltans mothers moved about randomly in the arena instead of going directly to their cocoon, suggesting that their visual system differs from that of $L$. tarantula and is not used in this case.

When mothers touched their cocoons with their palps or first three pairs of legs, they immediately grasped it between their legs and began to manipulate it. We suppose that during this contact they perceive tactochemical stimuli as do other spider species (Barth \& Schmitt 1991; Fujii 1980). Durations of this manipulation did not vary significantly among mothers. We hypothesize that the egg-sac emits chemical cues that stimulate manipulation to maintain contact with the mother. Every mother attaches her cocoon directly to her spinnerets after this manipulation, contrary to Pardosa tristis (Moffett \& Doell 1980). "Day 0" females did this faster than the others. We noted that it was harder to separate cocoons from their mothers on "day 15 " and "day 10" than on "day 0 ". We hypothesize that longer the attachment period the more care spiders take to attach older egg-sacs to their spinnerets. Weight and volume of egg-sacs did not vary with age, but maternal effort and overall investment were more important when egg-sacs were older. So females with "day 10" and "day 15" egg-sacs probably attach them with more care (more silk and better technical skills). Mothers' locomotor activity and behaviour after attachment were similar to those before loss. This similarity supports the previous hypothesis predicting that the behaviour observed during loss of egg-sac is searching. However, "day 15" mothers did not detach and manipulate their cocoons contrary to before the loss. This could be explained by the fact that they had just attached it.

$<\mathrm{H} 1>5$ - Conclusion

Wolf spiders' egg-sac carrying and maternal behaviour appeared to be chronologically linked to females' physiological state and maybe age of cocoon. Mothers manipulate their cocoon only after carrying it for at least 10 days. Mothers do not change their locomotor activity when their egg-sac is attached to their opisthosoma, but when they lose their egg-sac they modify their locomotor activity and behaviour so as to retrieve it. All mothers display this behaviour and its expression is linked to the age of the cocoon (or maternal time). Behaviour involving a cocoon appeared to be elicited by new stimuli from the egg-sac acting to maintain and develop maternal care. Further studies are necessary to verify that mother wolf spiders are able to recognize the developmental stage of the egg-sac, and to investigate stimuli (vibration or chemical) used during this maternal ontogeny.

\section{$<$ ACK $>$ Acknowledgements}

The authors would like to thank Dr Ann Cloarec (University of Rennes 1) and Prof. Simon N. Thornton (University of Lorraine) for reading the manuscript, Nathalie Morris and Céline Nicolle for animal maintenance (University of Rennes 1).

\section{$<$ REF $>$ References}

\section{$<$ BIBL $>$}

Barth, F. G. \& Schmitt, A.;1; 1991: Species recognition and species isolation in wandering spiders (Cupiennius spp.; Ctenidae). Behav. Ecol. Sociobiol. 29(5), 333-339.

Bonnet, P.;1; 1946: L'instinct maternel chez les araignées à l'épreuve de l'expérimentation. 
Bull. Soc. Hist. Nat. Toulouse, 81, 185-250.

Brach, V.;1;1976: Subsocial behavior in the funnel-web wolf spider Sosippus floridanus (Araneae: Lycosidae). Fla. Entomol. 59, 225-229.

Bradoo, B. L.;1; 1973: The cocoon spinning behaviour and fecundity of Stegodyphus sarasinorum Karsh (Araneae, Eresidae) from India. Or. Insects 6, 193-203.

Bristowe, W. S. 1958: The world of spiders. $<$ PL $>$ Collins, London $</ \mathrm{PL}>$.

Buskirk, R. E.;1; 1981: Sociality in the Arachnida. In Social Insects, vol. II (Hermann H. R., ed). $<$ PN $>$ Academic Press $</$ PN $>,<$ PL $>$ New York $</$ PL $>$, pp. 281-367.

Canard, A;1;. 1987: Analyse nouvelle du développement postembryonnaire des araignées. Rev. Arachnol. 7(3), 91-128.

Clutton-Brock, T. H.;1; 1991: The evolution of parental care. $<\mathrm{PN}>$ University Press $</ \mathrm{PN}>$, $<$ PL $>$ Princeton, New Jersey $</$ PL $>$.

Colancecco, M., Rypstra, A. L. \& Persons, M. H.;1; 2007: Predation and foraging costs of carrying eggsacs of different mass in the wolf spider Pardosa milvina. Behaviour 144(9), $1003-1018$

Culley, T., Wiley, J. E. \& Persons, M. H.;1; 2010: Proximate cues governing egg sac discrimination and recognition in the wolf spider Pardosa milvina (Araneae: Lycosidae). J. Arachnol. 38, 387-390.

Dolejš, P., Kubcová, L. \& Buchar, J;1;. 2010: Courtship, mating, and cocoon maintenance of Tricca lutetiana (Araneae: Lycosidae). J. Arachnol. 38, 504-510.

Eason, R. R.;1;1964: Maternal care as exhibited by wolf spiders (Lycosids). Ark. Acad. Sc. 
Proc. 18, 13-19.

Eason, R. R.;1; 1969: Life history and behavior of Pardosa lapidicina Emerton (Araneae: Lycosidae). J. $<$ PL $>$ Kansas $</$ PL $>$ Entomol. Soc. 42, 339-360.

Eberhard, W. G.;1; 1974: Maternal behaviour in a South American Lyssomanes. Bull. Br. Arachnol. Soc. 3, 51-52.

Escalante, I., Aisenberg, A. \& Costa, F. G.;1; 2015: Risky behaviors by the host could favor araneophagy of the spitting spider Scytodes globula on the hacklemesh weaver Metaltella simony. J. Ethol. 33, 125-136.

Fink, L. S.;1; 1987: Green Lynx spider egg sacs: sources of mortality and the function of female guarding (Araneae, Oxyopidae). J. Arachnol. 15 (2), 231-239.

Foelix, R. F;1; 2011: Biology of Spiders. $<$ PL $>$ Harvard $</$ PL $><$ PN $>$ University Press $</$ PN $>$,

$<$ PL $>$ Cambridge, Massachusetts, and London, England $</$ PL $>$.

Fujii, Y.;1; 1977: Examinations of the maternal care of cocoon in Pardosa astrigera L. Koch (Araneae, Lycosidae). J. Thermal Biol. 10, 171-175.

Fujii, Y.;1; 1980: Analytical study of maternal behavior in Pardosa astrigera L. Koch (Araneae, Lycosidae). Bull. Nippon. Dent. Univ. Gen. Ed. 9, 235-245.

Gertsch, W. J.;1; 1979: American spiders ( $2^{\text {nd }}$ edn $) .<$ PL $>$ Van Nostrand, New York $</$ PL $>$.

Hebets, E.A., Stratton, G. E. \& Miller, G. L;1;. 1996: Habitat and courtship behavior of the wolf spider Schizocosa retrosa (Banks) (Araneae, Lycosidae). J. Arachnol. 24, 141-147.

Horel, A. \& Gundermann, J. L.;1; 1992: Egg sac guarding by the funnel-web spider Coelotes terrestris: function and development. Behav. Process. 27, 85-94.

Humphreys, W. F.;1; 1974: Behavioral thermoregulation in a wolf spider. Nature, 251, 502503. 
Kaston, B. J.;1;1965: Some little known aspects of spider behavior. Amer. Midl. Naturalist. 73, 336-356.

Kight, S. L., \& Ozga, M.;1; 2002: Costs of reproduction in the terrestrial isopod Porcellio laevis Latreille (Isopoda: Oniscoidea): brood-bearing and locomotion. J. $<$ PL $>$ Kansas $</$ PL $>$ Entomol. Soc. 74, 166-171.

Krafft, B.;1; 1981: The significance and complexity of communication in spiders. In Spider communication: mechanisms and ecological significance (Witt, P.N. \& Rovner J. S., eds). $<$ PL $>$ Princeton $</$ PL $><$ PN $>$ University Press $</$ PN $>,<$ PL $>$ New Jersey $</$ PL $>$, pp. 15-66. Krafft, B. \& Horel, A.;1;1980: Comportement maternel et relations mères-jeunes chez les araignées. Reprod. Nutr. Dévelop. 20, 747-758.

Kullmann, E.;1; 1972: Evolution of social behaviour in spiders (Araneae; Eresidae and Theridiidae). Amer. Zool. 12, 419-426.

Lardies, M. A., Cotoras, I. S. \& Bozinovic, F.;1; 2004: The energetics of reproduction and parental care in the terrestrial isopod Porcellio laevis. J. Insect Physiol. 50, 1127-1135.

Li, D. \& Jackson, R. R.;1; 2003: A predator's preference for egg-carrying prey: a novel cost of parental care. Behav. Ecol. Sociobiol. 55, 129-136.

Lubin, Y. D.;1;1974: Adaptative advantages and the evolution of colony formation in Cyrtophora (Araneae, Araneidae). Zool. J. Linnaean Soc. 54, 321-339.

Marques, E. S. A., Vascocelos-Netto, J. \& de Mello, M. B.;1; 1998: Life history and social behavior of Anelosimus jabaquara and Anelosimus dubiosus (Araneae, Theridiidae). J. Arachnol. 26, 227-237.

Miller, G. L. \& Miller, P. R.;1; 1987: Life cycle and courtship behavior of the burrowing wolf spider Geolycosa turricola (Treat) (Araneae, Lycosidae). J. Arachnol. 15, 385-394.

Moffet, S. \& Doell, G. S.;1; 1980: Alteration of locomotor behavior in wolf spiders carrying normal and weighted egg cocoons. J. Exp. Zool. 213, 219-226.

Nørgaard, E.;1; 1951: On the ecology of two Lycosid spiders (Pirata piraticus and Lycosa pullata) from a Danish sphagnum bog. Oikos, 3, 1-21.

Nørgaard, E.;1; 1956: Environment and behaviour of Theridion saxatile. Oikos, 7, 159-192. 
Nyffeler, M., Sterling, W. L. \& Dean, D. A.;1;1994: How spiders make a living. Envr. Ent. 23, $1357-1367$.

Opell, D. B.;1;2001: Egg sac recognition by female Miagrammopes animotus (Araneae, Uloboridae). J. Arachnol. 29, 244-248.

Ortega-Escobar, J.;1; 2011: Anterior lateral eyes of Lycosa tarantula (Araneae: Lycosidae) are used during orientation to detect changes in the visual structure of substratum. J. Exp. Biol. 214, 2375-2380.

Palmgren, P.;1; 1944: Hymenopterous parasites in egg sacs of spiders of the genus Pardosa. Tijdschr. Entomol. 116, 43-61.

Papke, M. D., Reichert, S. E. \& Schulz, S.;1; 2001: An airborne female pheromone associated with male attraction and courtship in a desert spider. Anim. Behav. 61, 877-886.

Peck, W. B. \& Whitcomb, W. H.;1;1970: Studies on the biology of a spider Chiracanthium inclusum (Hentz). Agr. Exp. Sta. Div. Agr., Univ. $<$ PL $>$ Arkansas $</$ PL $>$ Bull. 753.

Randall, J. B.;1; 1977: New observations of maternal care exhibited by the green Lynx Spider Peucetia viridans Hentz (Araneae, Oxyopidae). Psyche, 84, 286-291.

Roberts, J. A. \& Uetz, G. W.;1;2004: Chemical signaling in a wolf spider: a test of ethospecies discrimination. J. Chem. Ecol. 30, 1271-1284.

Roland, C., Gundermann, J.L. \& Horel, A.;1; 1996: Maternal state induction in female spiders by the young. Behaviour 133, 1125-1131.

Rovner, J. S., Higashi, G. A. \& Foelix, R. F.;1; 1973: Maternal behaviour in wolf spiders: the role of abdominal hairs. Science 182, 1153-1155.

Royle, N. J., Smiseth, P. T. \& Kölliker, M;1;. 2013: The evolution of parental care. $<$ PN $>$ University Press $</$ PN $>,<$ PL $>$ Oxford $</$ PL $>$.

Rundus, A. S., Biemuller, R., DeLong, K., Fitzgerald, T. \& Nyandwi, S.;1;2015: Age-related plasticity in male mate choice decisions by Schizocosa retrorsa wolf spiders. Anim. Behav. 107, 233-238.

Seyfarth, E. A. \& Barth, F. G.;1;1972: Compound slit sense organs on the spider leg: 
Mechanoreceptors involved in kinesthesic orientation. J. Comp. Physiol. 78, 176.-191.

Shear, W. A.;1; 1970: The evolution of social phenomena in spiders. Bull. Brit. Arachnol. Soc. $1,65-76$.

Smiseth, P. T., Kölliker, M. \& Royle, N. J.;1; 2012: What is parental care? In The Evolution of Parental Care (Royle, N. J., Smiseth, P. T. \& Kölliker M., eds). $<$ PL $>$ Oxford $</$ PL $>$ $<$ PN $>$ University Press $</$ PN $>,<$ PL $>$ United Kingdom $<$ PL $>$, pp. 1-17.

Stefani, V., Moreira, S. \& Del-Claro, K.;1; 2011: Oviposition and post-embrionic development of Aglaoctenus lagotis (Araneae: Lycosidae). Zoologia, 28, 565-570.

Tallamy, D. W. \& Wood, T. K.;1; 1986: Convergence patterns in subsocial insects. Ann. Rev. Entomol. 31, 369-390.

Tammaru, T., Esperk, T. \& Castellanos, I.;1; 2002: No evidence for costs of being large in females of Orgyia spp. (Lepidoptera, Lymantriidae): larger is always better. Oecologia, 133, 430-438.

Tietjen, W. J.;1;1977: Dragline-followingby male Lycosid spiders. Psyche, 84 (2), 165-178. Toyama, M.;1;2003: Relationship between reproductive resource allocation and resource capacity in the matriphagous spider, Chiracanthium japonicum (Araneae: Clubionidae). J. Ethol 21, 1-7.

Vachon, M.;1; 1957: Contribution à l'étude du développement post-embryonnaire des araignées. Première note. Généralités et nomenclatures des stades. Bull. Soc. Zool. Fr. 82, 337-354.

Vannini, M., Contini Bonacossi, B. \& Ugolini, A.;1; 1986 : Cocoon care in Pardosa hortensis (Araneae, Lycosidae). Biol. Behav. 11, 85-96.

Viera, C., Ghione, S. \& Costa, F. G;1; 2007: Mechanisms underlying egg-sac opening in the subsocial spider Anelosimus cf. studiosus (Araneae Theridiidae). Ethol. Ecol. Evol. 19, 6167. 
Vlijm, L., Kessler, A. \& Richter, C. J. J. ;1;1963: The life history of Pardosa amentata (Cl.), (Araneae, Lycosidae). Ent. Ber. 23, 75-80.

Wagner, J. D. ;1; 1995: Egg sac inhibits filial cannibalism in the wolf spider, Schizocosa ocreata. Anim. Behav. 50, 555-557.

Wise, D. H. ;1; 1993: Spiders in ecological webs. $<$ PL $>$ Cambridge $</$ PL $><$ PN $>$ University Press $</$ PN $>,<$ PL $>$ UK $</$ PL $>$.

Whitcomb, W. H. \& Eason, R. ;1; 1964: A technique for determining the duration of egg incubation in wolf spiders. Turtox News 42, 301-302.

Whitcomb, W. H. \& Eason, R. ;1;1967: Life history and predatory importance of the striped lynx spider (Araneida: Oxyopidae). $<$ PL $>$ Arkansas $<$ PL $>$ Acad. Sci. Proc. 21, 54-58.

$</ \mathrm{BIBL}>$

$<$ Figure $>$ Figure 1: Mother Pardosa saltans with a 0-day old and a 15-day old egg-sac (A and A'). Embryonic development in relation to age of egg-sac: (B) egg stage; (C) pre-larva stage in 10-day old eggs; (D) pre-larva out of the egg after 15 days of development.

$<$ Figure>Figure 2: Pardosa saltans spiders' behaviour (in frequencies) during exploration: (A) virgins $(n=14)$ and mothers carrying a 0 -, 10 - or 15 -day old egg-sac $(n=57)$; (B) virgins and mothers after egg-sac loss; (C) virgins and mothers after contact and hanging of egg-sac. Frequencies were compared using $\chi^{2}$ tests: different letters indicate a significant difference at $\mathrm{p}<0.05$.

$<$ Figure $>$ Figure 3: Locomotor activity of virgins $(n=14)$ and mothers $(n=57)$ carrying their egg-sac (Test 1), after lost their egg-sac (Test 2) and after egg-sac hanging (Test 3): (A) distances covered by spiders ( $\mathrm{cm} / \mathrm{min}$ ) during the 3 tests; (B) surface explored (\%) during the 3 tests; (C) locomotion pattern of a mother during the 3 tests. Distances covered and surfaces explored were compared using ANOVAs: different letters indicate a significant difference at $\mathrm{p}<0.05, \mathrm{NS}=$ not significantly different.

$<$ Figure $>$ Figure 4: Latencies to egg-sac retrieval (sec), duration of egg-sac manipulation $(\mathrm{sec})$, and latency of egg-sac hanging $(\mathrm{sec})(\mathrm{n}=57)$. Latencies were compared using ANOVAs: different letters indicate a significant difference at $\mathrm{p}<0.05$.

TDENDOFDOCTD 


\section{Figures}

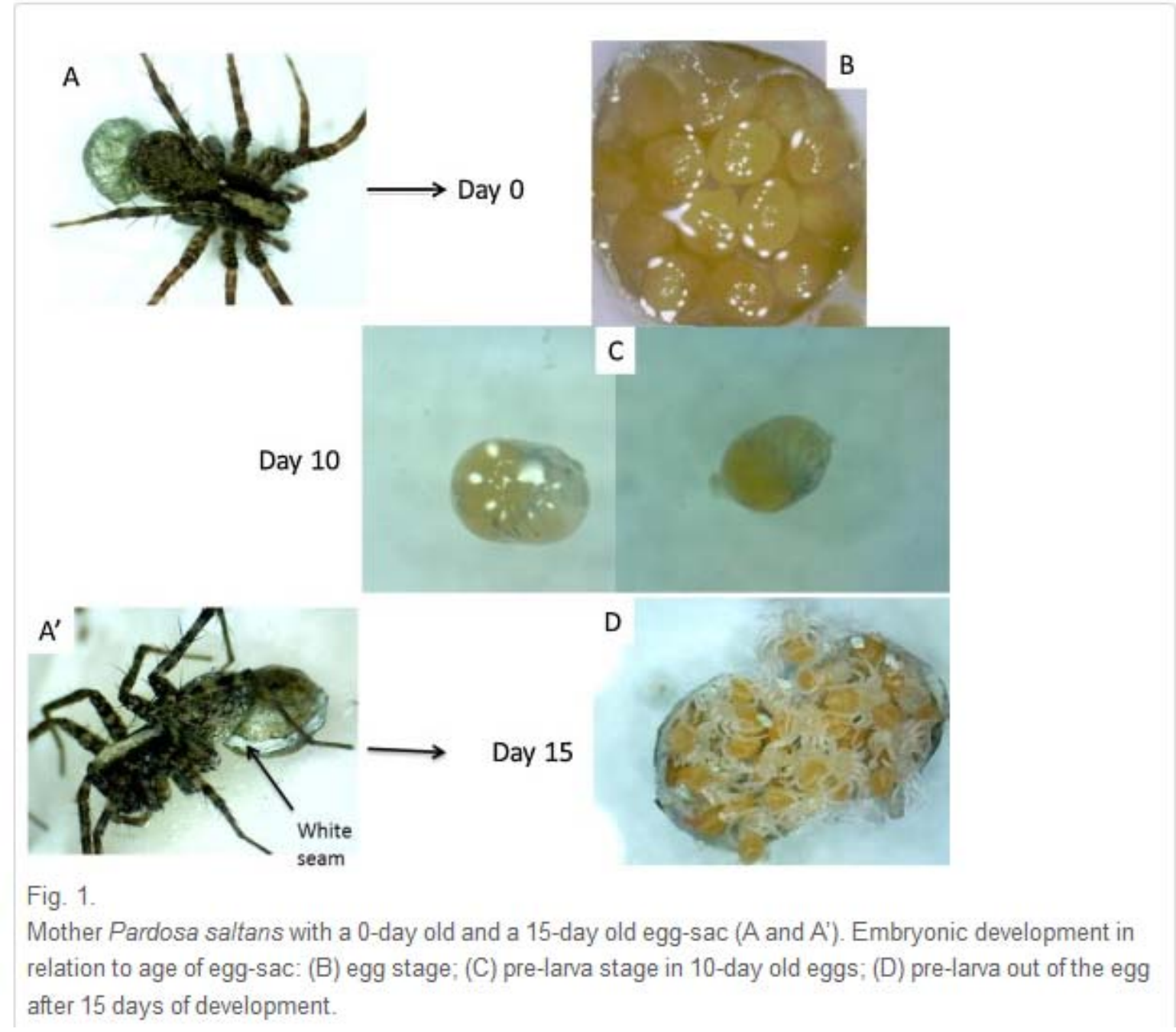




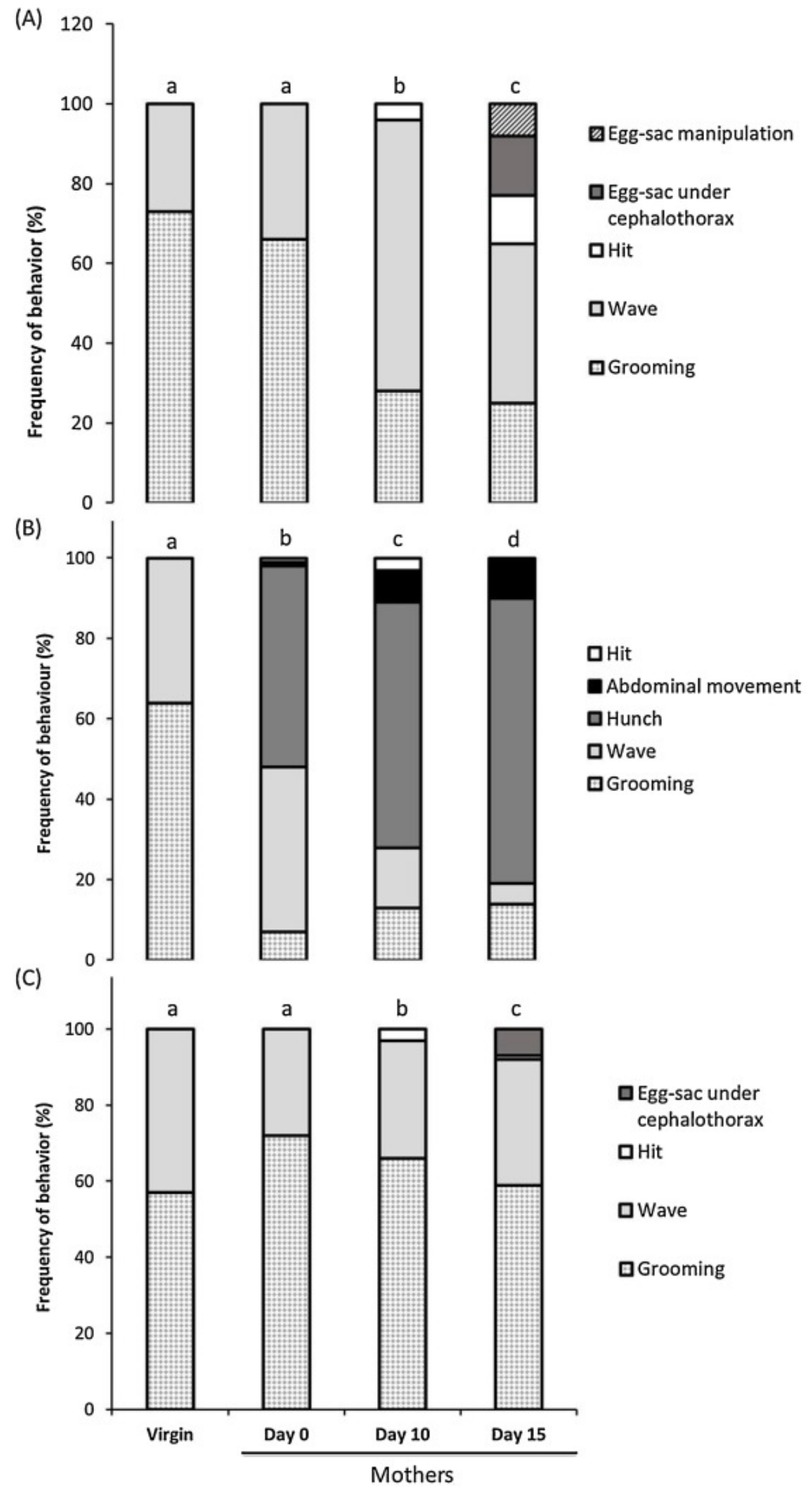

Fig. 2. 
Pardosa saltans spiders' behaviour (in frequencies) during exploration: (A) virgins $(\mathrm{n}=14)$ and mothers carrying a 0 -, 10 - or 15 -day old egg-sac $(\mathrm{n}=57)$; $(\mathrm{B})$ virgins and mothers after egg-sac loss; (C) virgins and mothers after contact and hanging of egg-sac. Frequencies were compared using $\chi^{2}$ tests: different letters indicate a significant difference at $p<0.05$. 


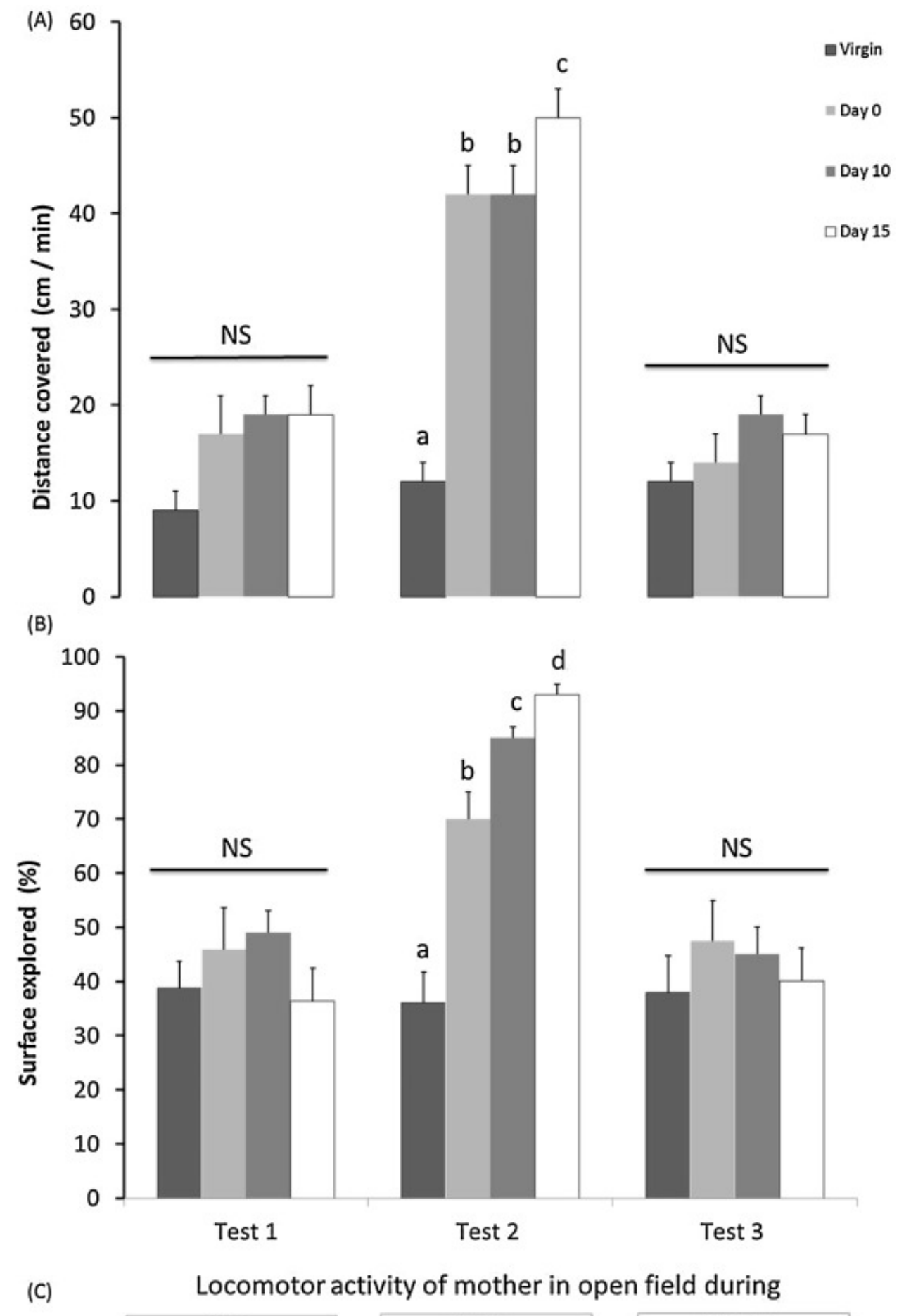

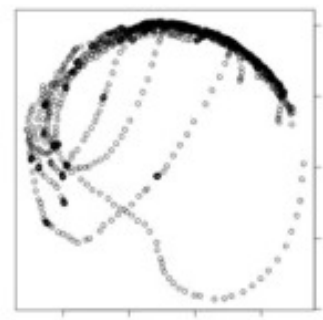

Test 1

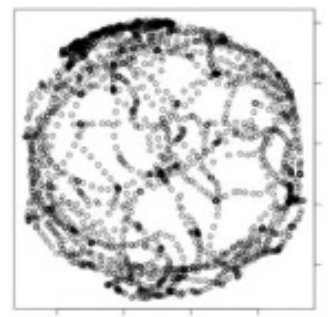

Test 2

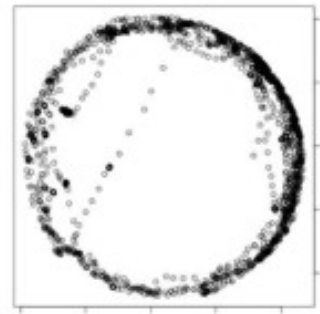

Test 3

Fig. 3.

Locomotor activity of virgins $(n=14)$ and mothers $(n=57)$ carrying their egg-sac (Test 1), after lost their egg-sac (Test 2) and after egg-sac hanging (Test 3): (A) 
distances covered by spiders ( $\mathrm{cm} / \mathrm{min})$ during the 3 tests; (B) surface explored (\%) during the 3 tests; (C) locomotion pattern of a mother during the 3 tests. Distances covered and surfaces explored were compared using ANOVAs: different letters indicate a significant difference at $\mathrm{p}<0.05, \mathrm{NS}=$ not significantly different.

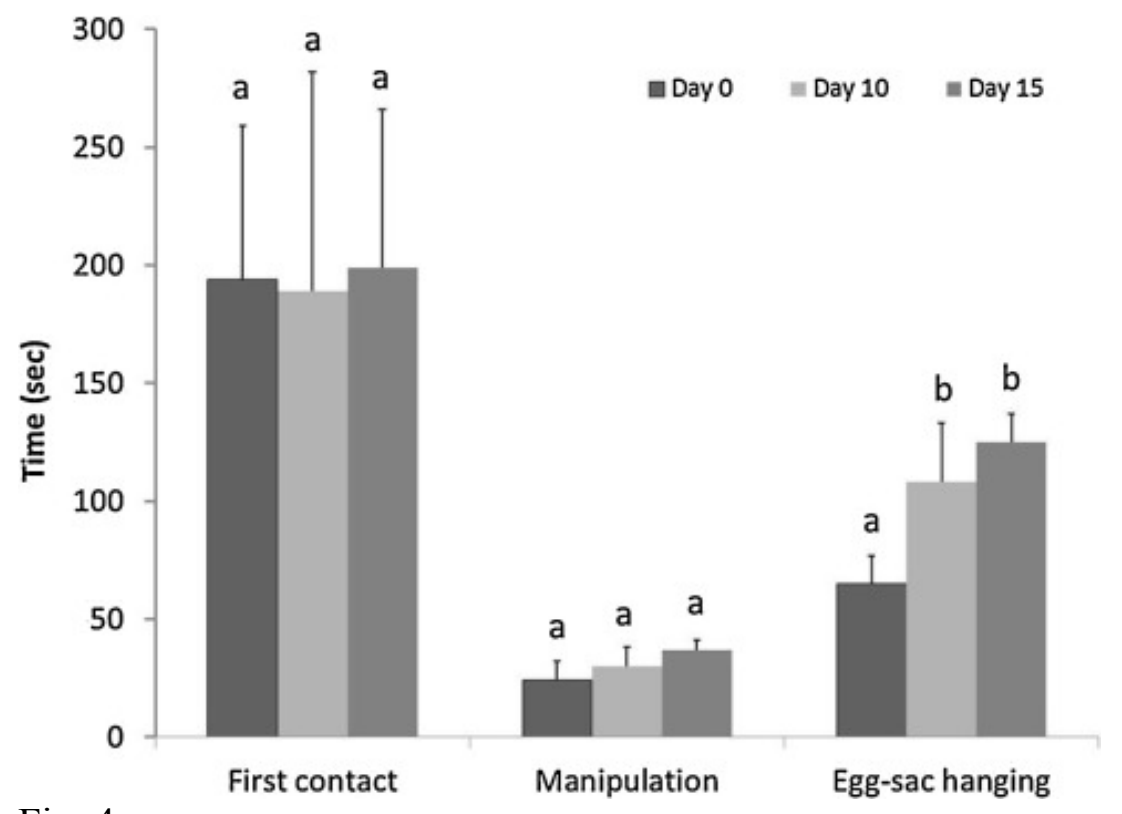

Fig. 4.

Latencies to egg-sac retrieval (sec), duration of egg-sac manipulation (sec), and latency of egg-sac hanging $(\mathrm{sec})(\mathrm{n}=57)$. Latencies were compared using ANOVAs: different letters indicate a significant difference at $\mathrm{p}<0.05$. 